\title{
PELAKSANAAN SHORT MESAGGE SERVICE (SMS) REMINDER DI RUMAH SAKIT SYAFIRA PEKANBARU
}

\author{
Tri Purnama Sari, Uci Gumarsih \\ Dosen dan Mahasiswa Prodi D3 Rekam Medik dan Informasi Kesehatan \\ STIKes Hang Tuah Pekanbaru \\ Email: tripurnamasariayi@gmail.com dan
}

\begin{abstract}
SMS Reminder is a Short Message Service that broadcast in one direction, which means that incoming SMS will not be replied by system, and serves to remind the user. The system will automatically send SMS to multiple phone numbers which have been entered in database previously. The delivery time of SMS must be in accordance with a predetermined scheduling. The purpose of this study is to get an overview of implementation on SMS Reminder activities at Syafira Hospital Pekanbaru. The method use in this research is descriptive qualitative approach. The numbers of informants were two people that officer and person in charge SMS Reminder section.

These results indicate that the Human Resources of SMS Reminder amounted to two person have educational backgrounds S1 and have been not trained specifically on SMS Reminder and the service of SMS Reminder have not Standard Operating Procedures (SOPs), as well as the lack of a telephone to perform SMS Reminder. Suggestions on this research is SMS Reminder officers should be trained in communication and procedures for the implementation of SMS Reminder and make Standard Operating Procedures (SOPs) so that the officer has a reference in carrying out their duties.
\end{abstract}

Keywords: Implementation, SMS Reminder

\section{PENDAHULUAN}

Menurut Organisasi Kesehatan Dunia (WHO), pelayanan kesehatan perlu dilakukan reformasi dengan melakukan organisasi sebagai asuhan primer, dengan demikian, secara sosial fasilitas pelayanan kesehatan tersebut akan lebih sesuai dan lebih merespon berbagai tantangan yang abadi dalam masyarakat guna menghasilkan keluaran yang lebih baik. Tujuan penyelenggaraan upaya kesehatan dalam pembangunan kesehatan adalah untuk mencapai derajat kesehatan masyarakat yang optimal. Undang-Undang Kesehatan No. 23 Tahun 1994 Pasal 4 menyatakan bahwa setiap warga negara mempunyai hak yang sama dalam memperoleh derajat kesehatan yang optimal (bermutu). Untuk itu, pemerintah bertanggung jawab untuk melakukan berbagai upaya yang memungkinkan pencapaian peningkatan derajat kesehatan masyarakat secara optimal (Ayubi, 2009).

Kebutuhan perusahaan untuk meningkatkan mutu jasa serta kepuasan pelanggan semakin besar karena perdagangan bebas yang terbuka dalam era globalisasi. Oleh sebab itu, perusahaan di dalam negeri diharapkan mempersiapkan diri untuk membina organisasi terutama sumber daya dan sistem untuk menghadapi kedatangan pesaing industri sejenis dan industri lainnya. Rumah sakit merupakan salah satu perusahaan yang dituntut mampu memenangkan persaingan. Untuk itu, rumah sakit harus mampu menyediakan dan memberikan jasa layanan kesehatan yang bermutu bagi pasien. Pelayanan jasa kesehatan yang bermutu merupakan isu untuk memenangkan persaingan bagi rumah sakit. Meningkatkan pelayanan dalam rangka meningkatkan kepuasan pasien, pihak-pihak yang berkompeten dengan rumah sakit selalu mencari upaya inovatif untuk meningkatkan mutu layanan kesehatan rumah sakit. Kualitas jasa pelayanan rumah sakit berdasarkan nilai pelanggan dapat bersifat tidak kasat mata (intangible) seperti keramahan, kecepatan, keterampilan dan komunikasi yang dilakukan oleh petugas pelayanan, maupun yang bersifat kasat mata (tangible) seperti fasilitas yang tersedia menyangkut kebersihan dan kenyamanan serta pelayanan pada instalasi gizi (Hafizurrachman, 2009). 
Short Message Service (SMS) Reminder merupakan SMS yang bersifat broadcast satu arah, yang berarti SMS yang masuk tidak akan dibalas oleh sistem, dan berfungsi untuk mengingatkan pengguna. SMS Reminder berbasis pada waktu yang telah dijadwalkan. Sistem akan mengirimkan SMS secara otomatis ke beberapa nomor telepon yang sebelumnya sudah dimasukkan dalam database. SMS dikirimkan secara broadcast. Waktu pengiriminan SMS harus sesuai dengan penjadwalan yang sudah ditentukan (Setiawan, 2009)

Berdasarkan survey awal di Rumah Sakit Syafira Pekanbaru bahwa pelaksanaan SMS Reminder di Rumah Sakit Syafira dimulai pada tahun 2012 dan hasil survey terdapat 2 petugas SMS Reminder di bagian informasi, SMS Reminder di Rumah Sakit Syafira yang bertanggung jawab atas penyampaian SMS Reminder kepada pasien adalah Petugas SMS Reminder, setiap minggu lebih kurang 300 pasien yang di SMS. Alur SMS Reminder yaitu surat kontrol layanan rawat jalan maupun rawat inap mengeluarkan surat kontrol dengan tanggal yang telah ditetapkan kemudian surat kontrol dikumpulkan oleh petugas dan mengelompokkan tanggal jadwal yang ditetapkan dari rumah sakit, kemudian petugas menghubungi pasien sesuai jadwal yang ditetapkan.

Kendala yang didapat pada data yang berhubungan dengan rekam medis, karna tidak lengkap nomor telepon yang dicantumkan di surat kontrol sehingga pelaksanaan SMS Reminder terhambat dengan mencari lagi berdasarkan nomor rekam medis yang ada pada surat kotrol tersebut. Sarana dan prasarana terkendala masih kurangnya program atau sistem, karena rumah sakit tidak ada sistem tersendiri, terkendala fasilitas telepon hanya satu yang disediakan akan tetapi memakai ada 3 devisi yaitu CSO, administrasi bahkan ada devisi lainya. Manfaat SMS Reminder yaitu menggingatkan pasien untuk kontrol kembali. Sedangkan mayoritas yang di SMS adalah di Poli kebidanan dan mata.

\section{METODOLOGI PENELITIAN}

Penelitian ini adalah deskriptif dengan pendekatan kualitatif dengan tujuan untuk membuat gambaran atau deskripsi tentang suatu objektif. Metode penelitian deskriptif digunakan untuk memecahkan atau menjawab permasalahan yang sedang dihadapi pada situasi sekarang (Notoatmodjo, 2005). Dalam penelitian ini mendeskripsikan pelaksanaan Short Message Service (SMS) Reminder di Rumah Sakit Syafira Pekanbaru.

\section{HASIL DAN PEMBAHASAN}

Berdasarkan hasil penelitian dari hasil observasi yang dilakukan penulis dibagian SMS Reminder di Rumah Sakit Syafira Pekanbaru dimana terdapat adanya Sumber Daya Manusia, SPO, dan Sarana dan Prasarana yang dapat dilihat pada tabel 1 dibawah ini:

Tabel 1. Hasil Observasi

\begin{tabular}{|c|c|c|c|}
\hline \multirow[b]{2}{*}{ No } & \multirow[b]{2}{*}{ Yang Diamati } & \multicolumn{2}{|c|}{ Keterangan } \\
\hline & & Ada & $\begin{array}{c}\text { Tidak } \\
\text { ada }\end{array}$ \\
\hline 1 & $\begin{array}{l}\text { Tenaga petugas di bagian } \\
\text { pengiriman SMS Reminder }\end{array}$ & $\sqrt{ }$ & \\
\hline 2 & Standar Prosedur Operasional & & $\sqrt{ }$ \\
\hline 3 & Alat yang digunakan handphone & $\sqrt{ }$ & \\
\hline \multirow{5}{*}{4} & Sarana & & \\
\hline & a. Computer & $\sqrt{ }$ & \\
\hline & b. Handphone & $\sqrt{ }$ & \\
\hline & c. Jaringan internet & $\sqrt{ }$ & \\
\hline & d. Program dan system & & $\sqrt{ }$ \\
\hline \multirow[t]{2}{*}{5} & Prasarana & & \\
\hline & Ruangan SMS Reminder & & $\sqrt{ }$ \\
\hline
\end{tabular}

Sumber:Data Primer Rumah Sakit Syafira pekanbaru

\section{Sumber Daya Manusia dibagian (SHORT MASSAGE SERVICE) SMS Reminder}

Berdasarkan hasil Wawancara penulis di lapangan dengan penanggung jawab SMS Reminder Di Rumah Sakit Syafira pekanbaru, diperoleh bahwa di bagian SMS Reminder Berjumlah 2 Orang petugas tamatan S1 IKM dan berbagi sift pagi dan sore, paginya yaitu untuk merekap data dan siangnya yaitu untuk pengsms pasien yang akan kontrol pada tanggal yang telah ditetapkan. Dari hasil wawancara mendalam penulis mendapatkan bahwa Sumber Daya Manusia atau petugas di bagian SMS 
Reminder ada 2 orang yang berlatar belakang pendidikan S1 IKM dan belum pernah mengikuti pelatihan tentang kegiatan SMS Reminder secara khusus Seperti pernyataan berikut:

"Sumber daya manusia atau petugas SMS Reminder di Rumah Sakit Syafira pekanbaru berjumlah 2 orang tamatan S1 IKM, yang mana 1 petugas SMS Reminder yang bertanggung jawab pada bagian peng-smsan pasien tersebut, kami juga belum pernah mengikuti pelatihan tentang SMS Reminder di Rumah Sakit Syafira pekanbaru secara khusus cuma kami pelatihan komunikasi yang baik dan benar itu yang diadakan dan diajarkan, yang diadakan sekali dalam 1 tahun oleh menajemen rumah sakit itu ada dek."(informan 1).

"dua orang dek, berlatar belakang pendidikan S1 IKM dan kami belum pernah mengikuti tentang SMS Reminder itu sendiri kami hanya mengikuti pelatihan tentang komunikasi yang diadakan dirumah sakit syafira sekali dalam 1 tahun dek."(informan 2)

\section{Standar Prosedur Operasional SMS} Reminder Di Rumah Sakit Syafira Pekanbaru Tahun 2015

Berdasarkan Hasil Wawancara penulis dilapangan bahwa Standar Prosedur Operasional (SPO) tentang SMS Reminder di Rumah Sakit Syafira Pekanbaru belum ada. Seperti yang dinyatakan oleh penanggung jawab SMS Reminder Di Rumah Sakit Syafira Pekanbaru berikut ini:

"Kalau standar prosedur operasional (SPO) di rumah sakit syafira ini belum ada dek, tapi langkah-langkah apa saja yang harus dilakukan masing-masing petugas sudah mengetahui, tapi Standar Prosedur Operasional secara sah dan tertulis belum ada dek."(informan 1)

"Standar Prosedur Operasional (SPO) di rumah sakit syafira ini belum ada dek, disini kami hanya menjalankan langkah-langkah yang sudah ada dek sebelumnya."(informan 2)

\section{Sarana Dan Prasarana yang digunakan} untuk SMS Reminder Di Rumah Sakit Syafira Pekanbaru Tahun 2015

Berdasarkan hasil Wawancara penulis di lapangan Terhadap informan bahwa sistem Sarana dan Prasarana yang digunakan untuk SMS Reminder di Rumah Sakit Syafira Pekanbaru ini masih manual dan kurangnya telepon seperti pernyataan berikut:

"Sarana dan Prasarana yang digunakan untuk SMS Reminder Rekapan data masih manual dek, terkendala masih kurangnya program SMS Reminder atau sistem, tapi untuk melihat nomor handphone pasien dilihat dikomputer dek berdasarkan nomor Rekam Medis yang ada pada surat kontrol tersebut dan masih kurangnya telepon yang menggunakan ada 3 devisi yaitu CSO, adminitrasi dan devisi lainnya."(informan 1).

"Sarana dan Prasarana disini kurangnya telepon, disini hanya ada 1 telepon yang digunakan dek." (informan 2).

\section{Pembahasan}

1. Sumber Daya Manusia dalam pelaksanaan SMS Reminder Di Rumah Sakit Syafira Pekanbaru Tahun 2015

Berdasarkan hasil Penelitian Sumber Daya Manusia di bagian SMS Reminder berlatar belakang S1 IKM berjumlah 2 orang. Yang mana 1 petugas SMS Reminder yang bertanggung jawab pada bagian peng-sms pasien tersebut, petugas belum pernah mengikuti pelatihan tentang SMS Reminder secara khusus. Petugas hanya mengikuti pelatihan komunikasi dengan baik dan benar.

Pendidikan dan pelatihan merupakan kegiatan yang harus dilaksanakan oleh Rumah Sakit agar pengetahuan (knowledge) Kemampuan (ability), dan Keterampilan (skill) mereka sesuai dengan tuntutan pekerjaan yang mereka lakukan. Dengan pengembangan ini diharapkan dapat memperbaiki dan mengatasi kekurangan dalam melaksanakan pekerjaan yang lebih baik dan sesuai dengan perkembangan 
ilmu dan teknologi yang digunakan oleh Rumah Sakit (Adisasmito,2010).

Berdasarkan Asumsi penulis bahwa Sumber Daya Manusia atau petugas dibagian SMS Reminder di Rumah Sakit Syafira Pekanbaru berlatar belakang S1 IKM yang belum pernah mengikuti pelatihan tentang SMS Reminder.

\section{Standar Prosedur Operasional (SPO) dalam pelaksanaan SMS Reminder Di Rumah Sakit Syafira Pekanbaru Tahun 2015}

Berdasarkan hasil penelitian sebagian besar informan mengatakan bahwa Standar Prosedur Operasional (SPO) tentang SMS Reminder belum ada secara tertulis dan sah. Tetapi petugas sudah mengetahui langkah-langkah apa saja yang harus dilakukannya.

Standar Prosedur Operasional adalah pedoman yang berisi prosedur-prosedur operasional standar yang didalam suatu organisasi yang digunakan untuk memastikan bahwa setiap keputusan, langkah, atau tindakan dan penggunaan fasilitas yang dilaksanakan oleh orang-orang dalam satu organisasi telah berjalan secara efektif, konsisten, standar dan sistematis (Tambunan, 2013).

Berdasarkan Asumsi penulis Standar Prosedur Operasional dibagian SMS Reminder di Rumah Sakit Syafira Pekanbaru tidak memiliki (SPO) secara sah dan tertulis. Mereka hanya mengikuti langkah-langkah yang sudah ada sebelumnya.

\section{Sarana Dan Prasarana dalam pelaksanaan SMS Reminder Di Rumah Sakit Syafira Pekanbaru Tahun 2015}

Berdasarkan hasil penelitian bahwa sistem Sarana dan Prasarana yang digunakan untuk SMS Reminder di Rumah Sakit Syafira Pekanbaru ini masih manual dan belum ada sistem komputerisasi tersendiri. dan terkendala fasilitas Telepon hanya 1 yang disediakan.

Menurut kamus lengkap bahasa Indonesia sarana adalah sesuatu yang dipakai sebagai alat mempermudah pekerjaan, maksud atau tujuan, syarat, upaya dan sebagainya, sedangkan prasarana adalah segala yang merupakan penunjang utama terselenggaranya sesuatu proses.

Secara umum sarana dan prasarana adalah alat penunjang keberhasilan suatu proses upaya yang dilakukan didalam pelayanan public, karena apabila kedua hal ini tidak tersedia maka semua kegiatan yang dilakukan tidak akan dapat mencapai hasil yang diharapkan sesuai dengan rencana (Laodesyamri, 2011)

Berdasarkan Asumsi penulis di bagian SMS Reminder di Rumah Sakit Syafira Pekanbaru bahwa Sarana dan Prasarananya masih kurangnya fasilitas telepon yang disediakan. Dan penambahan pulsa yang harus diperhatikan oleh rumah sakit tersebut.

\section{KESIMPULAN DAN SARAN}

\section{Kesimpulan}

1. Sumber Daya Manusia di bagian SMS Reminder berjumlah dua orang yang berlatar belakang pendidikan S1 IKM. Petugas SMS Reminder belum pernah mengikuti pelatihan secara khusus tentang SMS Reminder itu sendiri.

2. Standar Prosedur Operasional (SPO) Tinjauan pelaksanaan Short Message Service (SMS) Reminder dirumah sakit syafira belum ada secara tertulis, Petugas hanya mengikuti langkah-langkah yang sudah ada sebelumnya.

3. Sarana Dan Prasarana yang digunakan untuk SMS Reminder di Rumah Sakit Syafira Pekanbaru ini masih manual dan belum ada sistem komputerisasi tersendiri. dan terkendala fasilitas telepon hanya 1 yang disediakan akan tetapi memakai ada 3 devisi yaitu CSO, administrasi bahkan ada devisi lainnya.

\section{Saran}

1. Sebaiknya Rumah Sakit mengadakan khusus tentang SMS Reminder agar petugas dibagian unit Informasi lebih memahami dan menguasai tata cara SMS Reminder tersebut.

2. Sebaiknya Standar Prosedur Operasional (SPO) tentang SMS Reminder segera dibuat, 
agar petugas memiliki acuan dalam melaksanakan tugasnya.

3. Sebaiknya pihak Rumah Sakit menyediakan Sarana Dan Prasarana yang sesuai dengan kebutuhan Rumah Sakit dibagian SMS Reminder seperti ketersedian Handphone, pulsa, untuk peng-smsan pasien, agar kegiata yang dilakukan berjalan dengan lancar.

\section{DAFTAR PUSTAKA}

Alamsyah. D. (2011). Manajemen Pelayan Kesehatan. Yogyakarta: Nuha Medika

Arikunto.(2006). Prosedur Penelitian Suatu Pendekatan Praktik. Jakarta: Rineka Cipta.

Ayubi. (2009). Penilaian Kualitas Pelayanan Puskesmas dengan Model Donabedian: Studi Kasus Puskesmas di Kota Depok. Diakses dari www.jurnalkesmas.org/.../KESMAS_VOL_ 4_NO_1. Pada tanggal 13 Maret 2015.

Depkes RI. (2009). Rencana Pembangunan Jangka Pajang Bidang Kesehatan. Jakarta.

(2006). Pedoman Penyelanggaran Dan Prosedur Rekam Medis Rumah Sakit Indonesia. Jakarta.

Dian. (2010). SMS Based Gateway Patient Medication Reminder. Diakses dari www.academia.edu/.../SMS_Based_Gatew ay_Patient.Pada tanggal 13 Maret 2015.

Fantoni. A. (2006). Manajemen Sumber Daya Manusia. Jakarta: Rekam Cipta.

Hafizurrachman. (2009). Kepuasan Pasien dan KunjunganRumah Sakit. Diakses dari www.jurnalkesmas.or. Pada tanggal 13 Maret 2015.

Heru Cahya Rustamaji, Wilis Kaswidjanti,. (2008). Aplikasi sms pengingat ibu hamil. Seminar Nasional Informatika.

Indrianingsih, Yuliani. (2009). Aplikasi Berbasis SMS untuk Memperoleh Informasi Kurs Valuta Asing. Jurnal Sistem
Informasi.Vol.4 No. 2.

Matos and B. Blake. (2009). Public Emergency Wireless Phone System Computer Science dan Tehnology, Vol. 9, No. 1.

Notoadmojo. (2010). Metodelogi Penelitian. Jakarta:

Rineka Cipta. (2009). Pengembangan Sumber Dya Manusia. Jakarta: PT Rineka Cipta.

Sevani. (2013). SMS Based Gateway Patient Medication Reminder Application Aplikasi Reminder Pengobatan Pasien Berbasis SMS Gateway. Diakses dari jurnal.informatika.lipi.go.id/index.php/ink om/.../13. Pada tanggal 13 Maret 2015.

Sadeli, Muhammad. (2012). Aplikasi SMS Dengan Visual Basic 6.0 dan Visual Basic. Palembang: Maxikom.

Setiawan, S. Tedjokusum. and N. P. Suwanto. (2006). Perancangan Dan Pembuatan Sistem Layanan Sms Untuk Biro Administrasi Akademik Universitas Kristen Petra. Jurnal Informatika, Vol. 7, No. 1.

Setiawan, Alexander., Tedjokusuma. (2009). Perancangan dan Pembuatan Sistem Layanan SMS Untuk Biro Administrasi Akademik Universitas Kristen Petra. Jurnal Informatika. Volume 7 No.1.

Sugiyono (2011). Metode Penelitian Kualitatif Kulitatif Dan N Dan D. Bandung: Alfabeta.

Tambunan. R. (2013). Standard Opening Procedures (SPO). Jakarta: Maistas Publishing.

Undang - undang RI (2009). Nomor 36 Tahun Tentang Kesehatan. Bandung: Citra Umbara.

Zakaria. (2008). Aplikasi SMS Untuk Meningkatkan Pelayanan Kepada Pasien Di RS Immanuel Bandung, Jurnal Sistem Informasi, vol. 3 , no. 1. 